\title{
LIFE AND TRADITIONS
}

\section{THE RED MAN}

BY

\section{JOSEPH NICOLAR}

Old Tows, Maine

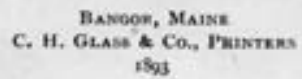

Original I 893 title page of The Life and Traditions of the Red Man 


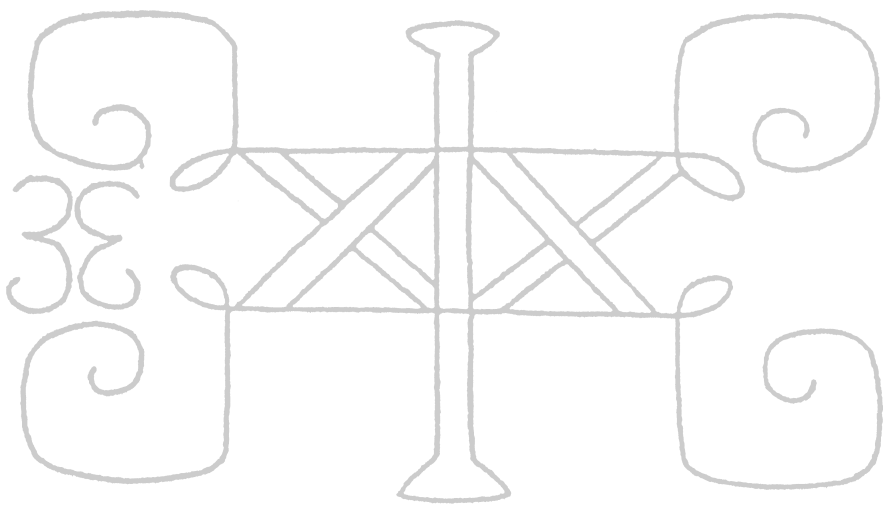




\title{
THE
}

\section{LIFE AND TRADITIONS}

\author{
OF THE RED MAN \\ *by * \\ Joseph Nicolar
}

Edited, Annotated, and with a History of the Penobscot

Nation and an Introduction by A N NETTE KOLOD N Y

Duke University Press

Durham and London

2007 
2nd printing, 2007

(C) 2007 Duke University Press

All rights reserved

Printed in the United States of America on acid-free paper @

Designed by C. H. Westmoreland

Typeset in Musee by Tseng Information Systems, Inc.

Library of Congress Cataloging-in-Publication Data appear on

the last printed page of this book.

Page ii: Double-curve design from Penobscot cape, denoting union of tribes assembled for a ceremony, from Frank G. Speck, The Double Curve Motive in Northeastern Art, I9I4. 